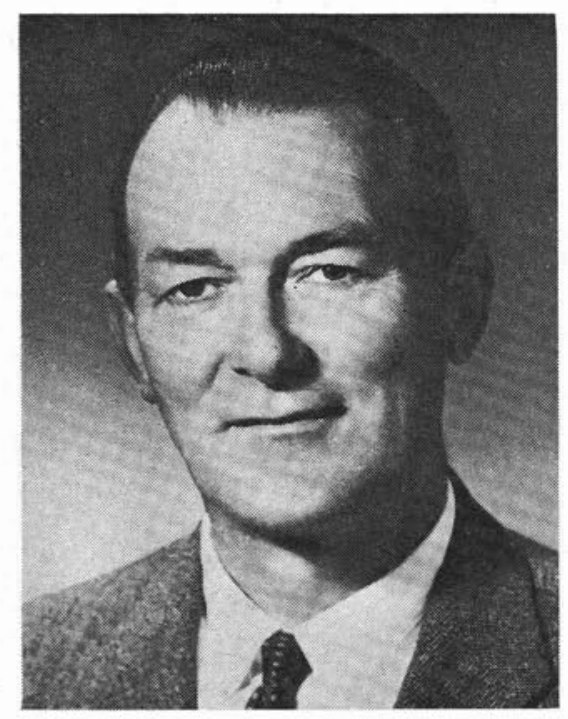

A. B. Anderson President

\section{The 68th Annual Meeting}

The 68th Annual Meeting of the Canadian Institute of Forestry/ Institut Forestier du Canada is now over. What kind of a meeting was it? In my opinion it was unequivocally a good meeting - a successful meeting - one in which those who attended found much to take back with them to their sections and fellow foresters.

Following the pattern of last year's annual meeting, this was a joint meeting with the provincial professional association - the Ontario Professional Foresters Association. Technical meetings, field trips and social events were joint, held in common, and only during the two business sessions did the two organizations meet separately. Co-operation in planning and execution was complete, with no conflict at anytime that I was aware of. There is no question that this kind of meeting can be successful if both parties wish it to be.

The theme of the joint meeting, Canada's Coniferous Forest A Growing Challenge, was developed by the technical sessions and the field trips. In particular, talks on silviculture and management of Swedish, Finnish and Southern U.S.A. coniferous forests by three speakers of international renown; Dr. B.K. Steenberg of the Royal Institute of Technology in Sweden, Dr. S.E. Appelroth of the Finnish Forest Research Institute, and Dr. R.C. Kellison of North Carolina University, gave us much to think about. The contrast of what we heard from these speakers, compared with what we heard earlier from the Canadian speakers on their problems in the various provinces, and with what we saw on the field trips, was startling - even though many of us were generally aware of the differences. That Canada's coniferous forest was a growing challenge came through loud, clear and emphatically.

There is no question in my mind, and, I am sure, in the minds of all foresters attending this meeting, that there is a growing depletion of Canada's forests, largely caused by a lack of initiative and incentive to provide for proper regeneration of the forests in all provinces. To a lesser degree incomplete utilization is also a contributing factor. It seems the only answer is political action which will ultimately persuade the federal and all provincial governments to assume their full responsibility toward the maintenance of our forests. This could be probably best accomplished by a combination of direct government action through the various forest services and by the enactment of laws and regulations that would provide the incentive for private industry to work in the same direction. Indeed, if we are to appreciate fully the messages delivered from Sweden, Finland and the U.S. South, the most practical way would be through close co-operation between industry and government, with the latter promoting the initiative and drive of the former through wise legislation and regulation. Failure to take effective action will soon result in economic and social hardships for Canadians in most walks of life.

The CIF/IFC can help to bring about this much needed better management of our forests, and it should not hesitate to do so. It is my earnest hope, during the next year, and thereafter, that the executive committee and all section councils will address themselves to this vital matter. 


\section{Introduction}

Today in Canada, an increasingly outdoorminded citizenry is becoming highly intolerant of damage to aesthetic values. As a result, the public is beginning to demand careful environmental planning on nearly every level of public and corporate land management. Logging is often bitterly attacked on environmental grounds. However, one of the impacts more commonly referred to is the adverse aesthetic effect of many clearcuts on the natural landscape. Thus the forest manager faces what appear to be conflicting demands on the forest resource. On one hand, he has to provide an ever increasing supply of forest commodities. On the other, he must also provide the less tangible, yet equally essential, benefits of a scenic landscape.

\section{The Visual Management Concept}

Most of Canada's public land is subject to man-made alterations - timber harvesting, power-line corridors, and road building for example. These activities are essential in most cases to the development of our expanding nation. But, if they continue to occur throughout the foreseeable future, how can such visible changes be reconciled with a quality environment?

The answer is by no means simple yet, over the past decade, a great deal of progress had been made, primarily in the north western United States, on the development of a visual management system. The basis of this system is the analysis of the visual vulnerability, or resistance, of a landscape to impact. Once this information is obtained development plans are then altered so as to minimize potential contrasts with the surrounding natural landscape.

Granted, such a system is not always feasible or applicable. However, in many of our more sensitive areas, such as high-use scenic roadways or land adjacent to parks, quality land management must incorporate visual concerns into the decision making process. This type of landscape management would do much to lessen conflicts between the forester and the public and, furthermore, such an operation does not always have to be elaborate and expensive. Often a small change in proposed cutting boundaries can do much to lessen visual impact at minimum additional cost. In a specific situation, this may only involve the elimination of geometric logging blocks in favor of more naturally shaped clearcut forms. But, regardless of what is done, some increased planning time, as well as a little creativity, will definitely be required. Furthermore, the successful implementation of such a system will only come after we, as a society, have recognized the existence and value of of aesthetics as a resource. Fortunately, the people in British Columbia have been endowed with a scenic resource comparable to any in the world. I only hope they do more to protect it in the future than they have done in the past.

Landscape management is a very complex procedure and involves a tremendous amount of inventory work before any on-site application can be attempted. In the inventory stage the visual variety of the landscape (an intermixture or succession of different things, forms, or qualities) must first be quantified in order to determine the ability of the landscape to absorb manipulation. When this information has been obtained the site must then be rated from a sensitivity aspect. This is primarily a social consideration and relates to the number of people, or recreational activities, that would be affected by the proposed development. This would complete the inventory process and an appropriate standard of exploitation could then be chosen. 


\section{Site Variety}

Variety classification establishes a value scale for the scenic quality of landscapes. The classification is based on the premise that all landscapes have some value, but those with the most variety or diversity have the greatest potential for high scenic value. A "distinctive" variety rating would refer to those areas where features of landform, vegetative patterns, water forms and rock formations are of outstanding visual interest. Thus, if logging were to occur on these sites, every attempt should be made to "blend in" the cutting blocks with the surrounding landscape. This would usually be achieved by designing the cut boundaries to look more like natural openings than like "checkerboard squares". Boundary layout would attempt to repeat or follow the form, line, color and texture ${ }^{1}$ that are already part of the natural scene, and thus, adverse visual contrasts with the natural landscape would be minimized.

\section{'Definitions}

1) form - The general shape of the landscape. (i.e. rugged mountains, rolling hills, etc.)

2) line - Something arranged in a row or sequence, or an intersection of 2 planes. In a landscape, this may refer to a ridgeline, a silhouette, or an avalanche line.

3) color - A phenomenon of light that enables one to differentiate otherwise identical objects. Thus, color variations existing in vegetation, soil, or rocks must be considered in landscape analysis.

4) texture - The visual or tactile surface characteristics of something. In other words, the overall detail or variety that exists in a site.

\section{Site Sensitivity}

A second major consideration in the inventory process concerns an analysis and ranking of site sensitivity levels. These are primarily measures of peoples' concern for the scenic quality of our forest land. Once again, a site must be intensively analyzed, this time to determine appropriate sight zones, land values, and existing recreational pursuits. Areas such as primary access highways, high-use recreation areas, and townsites must be considered as highly sensitive areas. Favorite canoeing or backpacking areas would also be considered as extremely sensitive. Annual visitation to these sites is usually low compared with the previously mentioned areas, but it is important to note that visitors to our backcountry are seeking a very natural experience. Therefore, any development that obviously modifies the natural landscape would have a detrimental effect on the quality of their experience.

After visually sensitive areas are established on a map, any activity that is to occur within their primary sight zones should be controlled to minimize adverse aesthetic contrasts. Obviously, distance zones come into play here as well, and should be considered in the planning process.

On sites with a good deal of variety, clearcut boundaries should attempt to blend in and follow the natural features wherever possible. This may prove extremely difficult to achieve in some areas and hence the more traditional methods of screening cuts from sensitive points of view should be employed.

\section{Conclusion}

Visual management has a definite future in British Columbia. I think it is interesting to note that in the northwest United States, the visual resource is considered equal to the fish, wildlife, and water resources. In many areas of British Columbia, the visual resource is certainly worthy of similar recognition. However, before this can occur there are certain obstacles to be overcome. To begin with, this province's logging guidelines are highly traditional and tend to encourage cardinal lines in logging boundaries. Another 
problem is generated by the matter of increased expenditures for the logger. Perhaps we should now give some thought to alternative systems of recreational funding that may encourage this type of management. Finally, we must also realize that successful implementation of visual planning could not be achieved through the application of any specific standards. The topography within B.C. is much too varied for such an approach. Therefore, more of a "sight" specific policy based on general guidelines and objectives would seem to be called for. These are all matters that must be dealt with before visual landscape management can become a reality on a large scale. However, it is something we must face in the very near future, if the rapid depletion of British Columbia's scenic resource is to be controlled before it is too late.

\section{Bibliography}

United States Dept. of Agriculture. 1974. National Forest Landscape Management - Vol. 2. USFS 47p. - Agr. Handbook 462

Litton, R.B., Jr. 1968. Forest landscape description and inventories ... a basis for land planning and design. Pacific S.W. Forest and Range Exp. Station, USDA For. Ser. Res. Pap. PSW - 49, 64p.

Appleyard, D.K. Lynch, and J.R. Meyer, 1964. The view from the road. Cambridge: MIT Press, 64p.

McDonald, P.M., and Raymond Whiteley, 1972. Logging a roadside stand to protect scenic values. J. For. p. 79.

\section{LETTERS}

"Mixedwood Forest Section" -

\section{Where is it in Alberta?}

May I take this opportunity to express my opinion, in fact a conviction, that took a lot of my free time and professional interest to evolve? I am sure it will be of interest to your readers.

The Mixedwood Forest Section is Section B18a of the Boreal Forest Region as defined in the Forest Regions of Canada by Rowe, (1972). This time-honored name belies the facts as they now exist. The change in forest species composition has been drastic. In Alberta, at least, the appropriate name for this Section should be Trembling Aspen-Black Spruce. The following evidence should prove convincing.

1. The name Mixedwood Section is confusing in itself. Any forest section is a mixedwood forest section in the literal sense, only the species composition varies. In Alberta, the Aspen-Grove and Mixedwood Sections are neighbours both geographically and floristically. Over a period of time the quantity of white spruce in the so-called Mixedwood Section has been progressively decreasing. Consequently, this section is now dominated by trembling aspen and black spruce. Therefore, what is good logic for the Aspen-Grove Section should be good logic for the Mixedwood Section. Why not then call a spade a spade?

2. The Alberta Forest Inventory (1968) clearly establishes that the Mixedwood Section is primarily characterized by an abundance of aspen, mixed with balsam poplar, white birch, white spruce and balsam fir. Black spruce and willows occupy extensive low-lying areas. Unfortunately, only a "broad inventory" was prepared. However, this inventory revealed some mature white spruce stands that have since been under harvesting, having reached their economic maturity.

3. Two fundamental factors affecting the Alberta Mixed Section need our serious attention. They are: agricultural expansion and forest fires. Agricultural expansion is taking place up to the northern limits of this section. Not long ago the Alberta Land Forum confirmed this fact. Consequently, white spruce has succumbed to the power saw.

The effects and losses by forest fires in Alberta are imprecisely known. However, several hundreds of forest fires, ranging from "moderate to severe in intensity" occur yearly in the Mixedwood Section.

The ecology and silvics of aspen are quite familiar, and there is no need to cover the welltrodden ground. The evidence is clear that at one time aspen extended up to the MacKenzie delta. The hardiness and obstinacy of aspen are beyond doubt. This species "thrives on fires", being well adapted to spread vegetatively. On the other hand, white spruce needs special conditions such as clean germination sites and prolific seed years. It appears that in Alberta conditions agricultural expansion, forest fires and forest harvesting overwhelmingly favour aspen. It is only reasonable that we recognize this fact squarely. Mr. Steele, Alberta Deputy Minister for Forests, recently thus ob- 
served: "protection against forest fires in the northern parts of the province had been non-existent. Many areas that were surveyed showed little sign of spruce regeneration. Our job in Alberta is difficult because of the climatic conditions of high temperatures, long days, low precipitation, and high incidence of lighting compared to many other parts of Canada."

4. The writer, as a project leader of the Alberta Biophysical Team, had the opportunity of closely examining the aerial photo-interpretation of a sizable area of the Alberta Mixedwood Section and for three summers did fieldwork and covered a wide swath of the Mixedwood Section (from Slave Lake to High Level) by road and air. This examination leaves no doubt in his mind that the dominant tree is the trembling aspen and its dominance is spreading by the year.

5. J.S. Rowe has very wisely refused to equate his "regions", and "Sections" with any ecological/climatic classification. No ecological or climatic criteria were first established by him and vegetation of Canada then pigeon-holed. On the contrary, his regionalization is visual, practical and operational, and is evidenced by a broad uniformity both in physiogonomy and the composition of the dominant forest formations. Rowe describes what he sees or, to use his phrase, his regions and sections are designed "from above", rather than "from below".

The need for name change of the Alberta Mixedwood Section is in line with Rowe's criterion of seeing forest formations "from above". What we see "from above" now is significantly different from what is conveyed by the name Mixedwood Section.

Forest Regions of Canada is a widely-used reference that treats the entire Canadian vegetation within one cover. It is only natural that at a national scale, the above anomaly - a result of the recent past - could not be documented.
However, for the sake of clarity and standardization of terminology such ambiguities need be pointed out.

Prem Kumar

\section{A Word of Advice}

May I present at least one set of answers to Mr. Dolynchuk.

I doubt if the majority of employers expect a newly qualified forester to be experienced; I suspect $\mathrm{Mr}$. Dolynchuk may have applied for positions for which he was not qualified because an experienced forester was required. In my experience most large companies and all governments do hire raw recruits every year. It is however true that experience gained as a student may prove to be a deciding factor. I have been surprised to find that some proportion of every graduating class have no, or, minimal, woods experience - they did not seem to think the summer experience of value.

Secondly, I doubt if we are graduating too many foresters. Rather it is our governments and industries who are at fault. The general level of Canadian forest management is horribly low. However in the mad rush for more and more of this world's goods we cannot afford more than a minimum. It will likely continue this way till trees get votes or this country comes to its senses.

And now a word of advice to Mr. Dolynchuk. Letter writing rarely produces a job. Visit your potential employer, sell yourself, look clean and neat, have your transcripts and references with you. Finally, try starting at the bottom of the ladder, do as many graduates have done; look for a job as a tree planter, chokerman or compassman. You will learn - if you have the mind to much you weren't taught at school and, if you do a good job, you will be noticed and promoted.

D. L. Handley

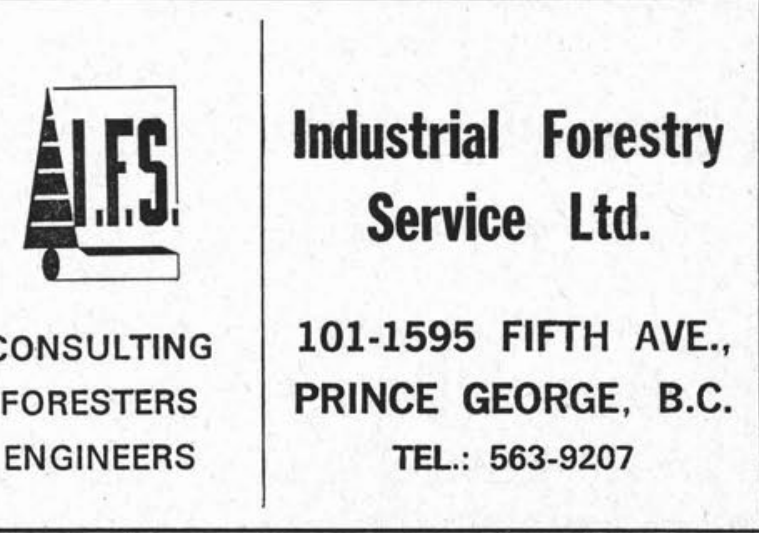

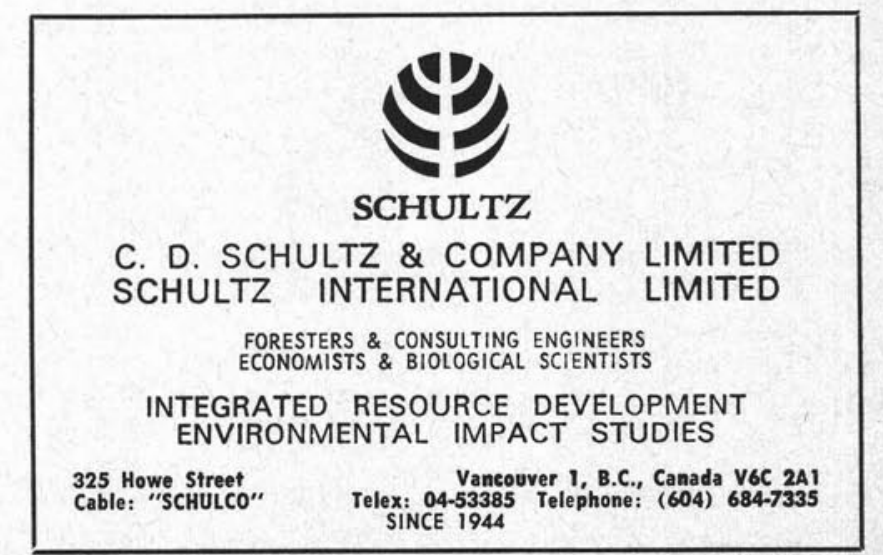

